\title{
British research councils win and lose
}

London. Britain's Science and Engineering Council (SERC) seems to have been the chief loser in a redistribution exercise ahead of the shift from five to six research councils due next year.

Notably, SERC has lost its bid to keep bioengineering under the same roof as other branches of engineering. Proposals put to the government last week on implementing June's white paper (policy document) on science would transfer most research into the engineering dimensions of biotechnology to the new Biotechnology and Biological Sciences Research Council (BBSRC).

That is a victory for Tom Blundell, the chairman of the Agriculture and Food Research Council, who has argued strongly for an expanded role for his council. Under its new name, the council will be responsible for research ranging from basic biology to its industrial applications, and will as a result see its budget rise by 40 per cent, from $£ 117$ million ( $\$ 175$ million) to $£ 167$ million.

That will disappoint the Science and Engineering Council, due to split into two organizations: the Engineering and Physical Sciences Research Council (EPSRC) and the Particle Physics and Astronomy Research Council (PPARC). While accepting the idea of a research council spanning basic and applied biology, SERC officials had urged that bioengineering should keep close links with other engineering disciplines.

"The government has been keen to set up a credible biotechnology council, but its efforts have perhaps been at the expense of engineering, since it does not seem to be concerned about doing something equally credible for engineering research", Sir Mark Richmond, the chairman of the SERC, said this week.

The so-called "boundary study" is by Sir David Phillips, who remains chairman of the Advisory Board for the Research Councils until the end of the year, but was in this case acting as Director General (DG) for the Research Councils, a new position whose creation was one of the key recommendations of the white paper.

The main thrust of the study has been to identify specific areas of responsibility for the six new research councils (see figure), each of which will be expected to fund both basic and applied research considered germane to a clearly defined mission. Biotechnology, occupying a grey area between the life and the physical sciences, has proved one of the most troublesome issues.

One of the few compromises is on biomolecular science, which chemists had feared might be absorbed into the new research council. According to a draft of

ity" for supporting research unable to find a natural home - a task previously taken on, not always willingly, by SERC.

Concern over whether the new director general will have sufficient authority and influence to prevent important research from falling through the cracks was expressed last week by several members of the House of Lords Select Committee on Science and Technology. "Put bluntly, the DG must have clout", said Lord Dainton, who chaired the committee's recent inquiry on the neglect of taxonomy.

William Waldegrave, the minister for science, reassured the committee that the new post was a "key role", since its occupant would be required "to shape the direction and strategy of the research base". Waldegrave said that the research council heads will continue to report directly to the

Phillips's conclusions, there will instead be a joint committee between the BBSRC and the EPSRC, with funds placed in a common pot by the two bodies - an arrangement meant to protect resources at present allocated to chemistry.

SERC had been hoping for a similar compromise for biochemical engineering, but Phillips came down clearly in favour of shifting that to the new biotechnology council, on the grounds that research in that field will contribute to BBSRC's role in supporting Britain's biology-based industry.

An early draft of the boundary study also suggested that funding for biosensors research be allocated to the engineering council, on the grounds that it would "sit more comfortably" next to molecular electronics and other sensor technologies. But Phillips is reported to have changed his mind, and to be suggesting in his final report that this too should go to the biotechnology council.

A less controversial Phillips proposal is that responsibility for Earth observation, atmospheric chemistry and science-based archaeology, previously funded by SERC, should be moved to the Natural Environment Research Council (NERC). He points out that the move puts responsibility on the NERC for developing the technological support required by each of these areas.

Providing clear mission statements to each of the research councils will, as Phillips acknowledges, mean that none will have the role of "residual responsibil- minister (and not through the DG). But he defended this decision on the grounds that the minister would rely on the DG to check that the research councils were fulfilling their responsibilities, and "are not just paying lip service to their mission statements".

David Dickson

The Office of Science and Technology is to organize seven regional seminars in different parts of Britain over the next few months to generate support for its "technology foresight" programme. That initiative, launched in the white paper, aims to build consensus on the key generic technology of the future, and on the orientation of the research community's efforts to those ends.

Waldegrave this week told a meeting of the Confederation of British Industry, which enthusiastically supports the foresight initiative (and will help to organize at least two of the regional meetings), that the approach is similar to that successfully applied by the Japanese government to identify areas requiring greater research effort.

Waldegrave said he wanted to use the technology foresight initiative to build "more intimate, regular and structured contact between the scientist and engineer at the bench and the industrialist". He hopes the seminars will "develop a commitment to the programme" across all sectors of the community; industrialists, academics, consumer bodies and representatives from the public sector will be invited to them. 